\title{
Fractal Dimension of Seismicity at Cangar, Arjuno-Welirang Complex, East Java
}

\author{
Rendi P. H. Sari, Rohmatul Uluwiyah, Sukir Maryanto, Didik R. Santoso
}

\begin{abstract}
This study aimed to determine the value of fractal dimensions in the Cangar region, Arjuno-Welirang Volcano Hosted Geothermal System (VHG) based on seismic time series data. The determination of fractal dimension values is done using the delay embedding theorem method. The process starts from determining the value of the delay time by using the autocorrelation function and also determining the value of embedding dimensions using the False Nearest Neighbors (FNN) method. These two parameters are used to reconstruct the attractor diagram. Quantization of the attractor diagram provides a correlation dimension curve that is directly related to the fractal dimension value. The fractal dimension value in the study area tends to be high, ranging from 5.43 to 6.29. This high value is associated with the amount of energy needed by hot water to make their way out to the surface through rock with very little permeability. The emergence of fractures due to the continuous heat discharge process in Cangar hot water and the gas release process triggers the appearance of seismic signals.
\end{abstract}

Keywords : Correlation Dimension, Delay Time, Embedding Dimension, Fractal Dimension.

\section{INTRODUCTION}

The fractal dimension can show the dynamics of a system both spatially and temporally. Spatial-temporal variations of fractal dimensions show invariance of the space scale that changes with time [1]. Barbano et al (2000) in their research on Mt. Etna shows that variations in fractal dimension values have a relationship with the fracturing process that affects the movement of magma in the volcano [2]. At the beginning of the eruption period, their seismicity is randomly distributed. The randomness gets greater over time but is clustered or concentrated on a fixed system. Caruso et al (2006) also identified this clustering on Mt. Hellens and shows that during the non-eruption period, the fractal values in St. Hellen are more stable and have a high value, although there is a decrease in the likelihood of a small eruption accompanied by a seismic swarm. When an eruption occurs, the fractal value decreases and is clustered, but during non-eruption, the seismic event is distributed randomly and

Revised Manuscript Received on January 10, 2020.

* Correspondence Author

Rendi P. H. Sari, Physics Department, Universitas Brawijaya, Malang, Indonesia. Email: shellyhabsari@gmail.com

Rohmatul Uluwiyah, Brawijaya Volcano and Geothermal Research Center, Universitas Brawijaya, Malang, Indonesia. Email: rohma.vrh@gmail.com

Sukir Maryanto*, Physics Department, Universitas Brawijaya, Malang, Indonesia, Email: sukir@ub.ac.id

Didik R. Santoso, Physics Department, Universitas Brawijaya, Malang, Indonesia, Email: dieks@ub.ac.id uniformly in its window [1].

We know that the entire system on earth is a nonlinear system. Dimensions in a system are sometimes not just 1, 2, or 3 dimensions. Fractal dimension is a way to quantify this dimension and its value is in the form of fractions. The most common method to determine fractal dimension values is Box Counting Dimension [1], [3], [4]. This method is used by partitioning object shapes into squares, then fractal dimension values are determined based on mathematical logarithmic calculations. But this fractal dimension calculation can be done if we already know the shape of the system.

This research aimed to determine the value of fractal dimensions in the Cangar region, Arjuno-Welirang Volcano Hosted Geothermal System (VHG) based on seismic time series data. Box counting method is difficult to do for time series data due to its independent and dependent variables have different units thus the scale of the ratio cannot be determined clearly. Therefore, to calculate fractal dimensions using the time series data itself, a method called the delay embedding theorem by Takens (1981) is used [5], [6]. Sauer et al (1991) apply the theorem created by Takens (1981) mathematically by reconstructing phase space in time series data [6].

In this study, the value of fractal dimensions will be carried out based on the delay embedding theorem by calculating the parameters such as delay time and correlation dimensions. These two parameters will be used for the reconstruction of the attractor diagram. The quantization results from the attractor diagram will be used to identify the fractal dimension value. The results of the fractal dimension values will be used to identify preliminary stages related to dynamic processes that exist in the Cangar region, Arjuno-Welirang VHG, East Java, Indonesia.

\section{MATERIALS AND METHODS}

Seismic signals were recorded in the Brawijaya Volcano and Geothermal Research Center Cangar Agro Techno Park Laboratory Building in 2015, 2016, and 2018. Data were recorded using a TDL-303S single station 3 component portable seismograph that has a frequency response of 0.005 $\sim 200 \mathrm{~Hz}$ and a sampling interval of 0.01 seconds.

Calculation of fractal dimension value starts from determining the delay time $\tau$ by using the autocorrelation function. Delay time value is determined when the time-lag of the autocorrelation reaches the first zero crossings and then the time-lag is multiplied by the sampling interval. The next step is to 
making attractor diagram in the phase space by returning the number of coordinates $m$ corresponding to embedding dimensions.

The appropriate embedding dimensions for reconstructing the phase space in the attractor diagram are determined when the False Nearest Neighbor (FNN) is zero [7].
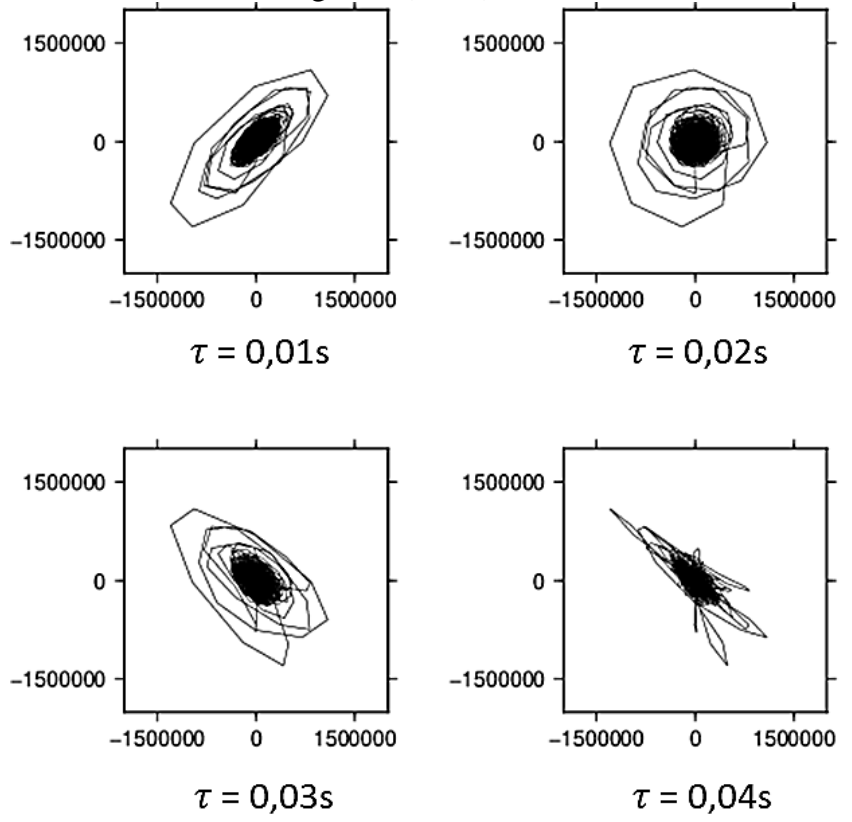

Fig. 1. Attractor Diagram for seismic event on November 26, 2016 at 12:54:00 with a delay time of $0,01 s ; 0,02 s$; $0,03 \mathrm{~s} ;$ and $0,04 \mathrm{~s}$. The appropriate delay time value to be used as a parameter for determining fractal dimension values is when $\tau=\mathbf{0 , 0 2 s}$.

The attractor diagram generated from the nonlinear dynamics system gives rise to fractal structures which are estimates the dimension shapes of time series data [8]. The quantization of the fractal structure formed is called the fractal dimension and one of the methods for determining its value is the correlation dimension. The correlations on the number of $N$ points in the attractor diagram and the results of the dimensions of embedding at distance $r$, is defined as (1) [3]:

$\mathrm{C}_{\mathrm{n}}(\mathrm{r})=\lim _{\mathrm{n} \rightarrow \infty}\left(\frac{1}{\mathrm{~N}(\mathrm{~N}-1)}\right) \sum_{\mathrm{i}_{\mathrm{j} j}=0, \mathrm{i}, \mathrm{i} ; \mathrm{j}}^{\mathrm{N}-1} \mathrm{H}\left(\mathrm{r}-\left\|\overrightarrow{\mathrm{y}}_{\mathrm{i}}-\overrightarrow{\mathrm{y}}_{\mathrm{j}}\right\|\right)$

$H(x)$ is a Heaviside function. $H(x)=0$ if $x<0$ and $H(x)=1$ if $x \geq 0$. The $\left\|\overrightarrow{y_{i}}-\overrightarrow{y_{j}}\right\|$ is a constant used as a measure of the euclidean distance (the sum root of squared components). In time series data analysis with definite precision and length, the range is $r \in\left(r_{\text {min }} \gamma_{\text {max }}\right)$, thus it can be assumed that $C_{n}(r) \sim P^{D_{2}}$. Therefore, the correlation dimension $D_{2}$ for time series attractor diagram can be calculated with (2) [3]:

$$
\mathrm{D}_{2}=\lim _{x \rightarrow 0} \frac{\ln \left(\mathrm{C}_{\mathrm{n}}(\mathrm{x})\right]}{\ln x}
$$

\section{RESULT AND DISCUSSION}

Determination of the appropriate delay time and embedding dimension is needed in the attractor diagram reconstruction. Sometimes the first zero crossings of delay time by autocorrelation method can not be determined. To overcome those situations, it is necessary to reconstruct the attractor diagram with different delay times in order to obtain the correct delay time value. Fig. 1 shows an attractor diagram for events on November 26, 2016 with different delay times. If the delay value used is incorrect (smaller or larger than it should be), then the diagonal grouping points appear along the attractor diagram [9]. In Fig. 1, the exact phase space is shown in the attractor diagram with a delay time value of $0,02 \mathrm{~s}$. This attractor diagram is then quantized to get the fractal dimension value using the correlation dimension equation (2).

The result of the attractor diagram quantization is the relationship curve between the distance $r$ and the fractal dimension value $d_{2}$. In the dissipative system, as the distance increases for the embedding dimension value greater than one, the curve will collapse then flat and a plateau will appear in the scaling region. This plateau provides estimates of fractal dimension value.

In Fig. $2 \mathrm{a}$ and b, the plateau is clearly marked with a blue arrow for events on June 7, 2015 at 06:54:00 and on November 26, 2016 at 13:25:00. The estimated fractal dimension values, in this case, are 6,29 and 5,43. The absence of plateau was also identified in this study. Fig. 2c shows the seismic event on May 24, 2016 at 12:51:20. In Fig. $2 \mathrm{c}$, the gradient curves for each embedding dimension are found separately and not coincide. Failure to find this plateau is probably due to the incompatibility of the algorithm with the length of the data used on several events in this study. That can also happen because the noise content dominates the entire time series data used.

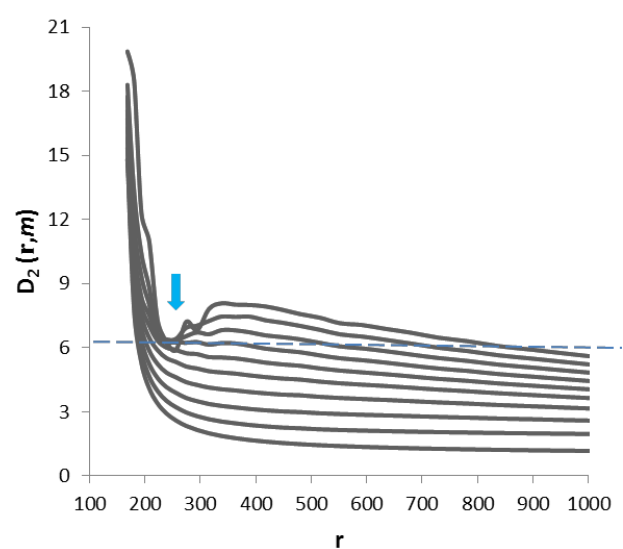

(a) 


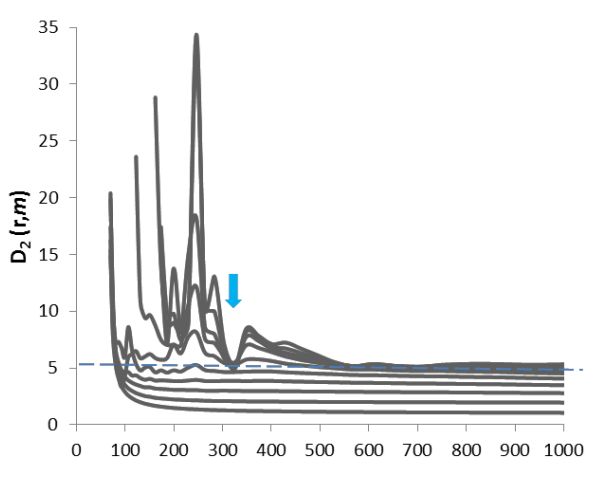

(b)

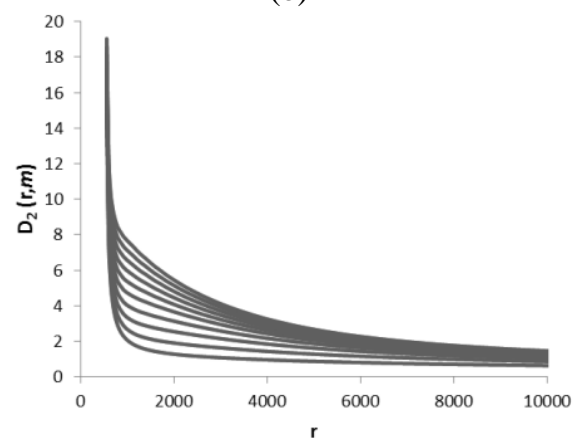

(c)

Fig. 2. Estimated fractal dimension value for the event on (a) June 7, 2015 at 06:54:00, (b) November

26, 2016 at 13:25:00, and (c) May 24, 2016 at

12:51:20. The blue arrow indicates the location of the plateau and the dashed line shows the estimated fractal dimension value for each event. Note that the curve (c) plateau cannot be found

The fractal dimensions obtained in this study ranged from 5,43 to 6,29 . The range of these values are high when compared to other studies in the volcano area. However, because this research was carried out in the Arjuno-Welirang VHG outflow area where the system is more complex due to the geological structure and dynamics of the hydrothermal fluid, it is possible for this value to occur.

The Cangar hot spring is an outflow zone resulting from flank eruptions of the Arjuno-Welirang volcano, Welirang lava, the Kembar volcano pyroclastic flow and the product of Anjasmara volcano. Some geophysical methods applied in this area show that this zone has a high rock density value (2-5 gr/cc) [10]. High-density rock values usually indicate that the zone is dominated by compact and impermeable rocks. The presence of hot water as one of the hydrothermal system convection result in the study area makes the pressure in the reservoir increase. The high-pressure hot water tries to find a gap thus it can rise to a surface whose pressure tends to be lower through structures in the form of faults or fractures. The more compact the rock that must be penetrated, the energy needed to flow hot water upwards will be greater thus seismic events occur due to this continuous heat discharge process [11], [12] and will increase the value of fractal dimensions.

Maryanto et al (2019) [12] linked the emergence of seismic activity in Cangar as a gas release process in immature hot water from the continuous heat discharge process as mentioned by Zobin (2013) [11]. Turcotte (1989) stated the effect of the rock fragmentation on the value of this large fractal dimension. Fractal dimension values of more than 3 indicate that the area under study is dominated by smaller rock fragmentation (rocks tend to be more compact). To create areas with smaller fragmentation tend to more require a lot of energy thereby increasing the value of density and fractals [13].

\section{CONCLUSION}

In this study the fractal dimension values obtained were quite high ranging from 5,43 to 6,29. These high values is associated with the amount of energy needed by hot water to make their way out to the surface through rock with very little permeability. The emergence of fractures due to the continuous heat discharge process in Cangar hot water and the gas release process triggered the appearance of seismic signals. The identification of fractal dimension values in this study is still the initial stage in analyzing seismic signals that exist in the Cangar area of the Arjuno-Welirang complex. Adding other parameters such as geological and geochemical parameters can show a source model that is likely to trigger the appearance of seismic vibrations in the study area.

\section{ACKNOWLEDGMENT}

This research partially was funded by Professor and Doctor Research Grant Faculty of Mathematics and Natural Sciences Universitas Brawijaya with Contract Number 25/UN10.F10/PN/2019 and Flagship Research Grant, Institute of Research and Community Services Universitas Brawijaya with Contract Number 697.20/UN10.C10 /PN/2019. The Authors thank the members of Brawijaya Volcano and Geothermal Research Center Laboratory to help the data acquisition. Portable seismograph type TDL-303S used in this research belongs to Meteorology, Climatology, and Geophysics Council Klass II Tretes and the data processing is carried out by using Tisean 2.1 free program by Hegger et al. 2000 (https://www.pks.mpg.de/ tisean/ TISEAN_2.1/index.html).

\section{REFERENCES}

1. F. Caruso, S. Vinciguerra, V. Latora, A. Rapisarda, and S. Malone. (2006, September). Multifractal Analysis of Mount St. Helens Seismicity as A Tool for Identifying Eruptive Activity. Fractals. 14(3), 179-186. Available: https://www.worldscientific.com/doi/abs/10.1142/ S0218348X06003180

2. M. S. Barbano, V. De Rubeis, P. Tosi, and S. Vinciguerra. (2000, April) Clustering Properties of Etna Seismicity During 1981-1991. Journal of Seismology. 4(2), 191-196. Available: https://link.springer.com/article/ 10.1023/A:1009845715642

3. C. Goltz, Fractal and Chaotic Properties of Earthquakes. New York: Springer Berlin Heidelberg, 1997.

4. V. Latora, A. Rapisarda, and S. Vinciguerra. (1998, December). A Fractal Approach to the Temporal Distribution of Microseismicity at the Low Eastern Flank of Mt. Etna During 1989-1994. Physics of the Earth and Planetary Interiors. 109(3-4), 115-127. Available: https:// www.sciencedirect.com/science/article/pii/S0031920198001241 
5. T. Buzug and G. Pfister. (1992, May). Optimal Delay Time and Embedding Dimension for Delay-Time Coordinates by Analysis of the Global Static and Local Dynamical Behavior of Strange Attractors. Physical Review A. 45(10), 7073-7084. Available: https://journals .aps.org/pra/abstract/10.1103/PhysRevA.45.7073

6. J. C. Robinson (2005, July). A Topological Delay Embedding Theorem for Infinite-Dimensional Dynamical Systems. Nonlinearity. 18(5), 2135-2143. Available: https://iopscience.iop.org/article/10.1088/0951$7715 / 18 / 5 / 013$

7. C. Rhodes and M. Morari. (1997, May). The False Nearest Neighbors Algorithm: An Overview. Computers and Chemical Engineering. 21 , 1149-1154. Available: https://www.sciencedirect.com/science/article/ pii/S0098135497876570

8. S. Maryanto, D. R. Santosa, I. Mulyana, and M. Hendrasto. (2011, July). Fractal and Chaos Properties of Explosion Earthquakes Followed by Harmonic Tremor at Semeru Volcano, East Java, Indonesia. International Journal of Sciences and Engineering Research. 2(7), 1-7. Available: https://www.ijser.org/viewPaperDetail.aspx?JUL1103

9. R. Uluwiyah, The Characterization of Tremor in Cangar Hotspring, Batu City. Malang, Indonesia: Universitas Brawijaya, 2019. (In Indonesian

10. M. N. Hadi, D. Kusnadi, and A. Sugianto. Integrated Investigation of Geology, Geochemistry and Geophysics of the Arjuno-Welirang Geothermal Region. Mojokerto and Malang Regencies, East Java Province. Bandung, Indonesia: Geological Resource Center, 2010. (In Indonesian)

11. V. M. Zobin, "Seismic Signals Associated With Geothermal Activity Within Volcanic Environment," in Complex Monitoring of Volcanic Activity, V. Zobin, Ed. New York, USA: Nova Science Publishers, 2013, pp. $171-188$.

12. S. Maryanto, R. P. H. Sari, R. Uluwiyah, and Abdurrouf. (2019, December). Preliminary Non Linear Analysis of Seismic Events Associated with the Hydrothermal of Cangar, Batu, East Java. TEST Engineering and Management. 81, 1638-1645. Available: http://www.testmagzine.biz/index.php/testmagzine/article/view/228

13. D. L. Turcotte. (1989, March). Fractals in Geology and Geophysics. Pageoph. 131(1/2), 171-196. Available: https://link.springer.com/ article/10.1007/BF00874486

\section{AUTHORS PROFILE}

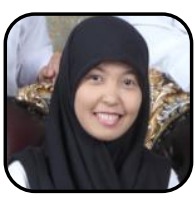

Rendi P. H. Sari was born in Bengkulu January 1st, 1994. She completed her undergraduate degree at Physics Department, Universitas Brawijaya, Malang in 2016 with geophysical Volcanology interest and is currently pursuing her master's degree at the same college since 2018. She has been active as a Research Assistant at the Brawijaya Volcano and Geothermal Research Center, Universitas Brawijaya since 2016 until now. Her current work is about the Linear and Nonlinear analysis of Seismicity in Arjuno-Welirang Complex, East Java, Indonesia.

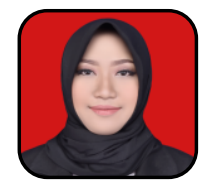

Rohmatul Uluwiyah completed her undergraduate study in the Physics Department, Faculty of Mathematics and Natural Sciences, Malang State University, East Java in 2015. She then pursued her master's study at Universitas Brawijaya in 2016 and graduated in 2019. She was part of a Research Assistant at the Brawijaya Volcano and Geothermal Research Center, Universitas Brawijaya. Her past work was about the landslide hazard analysis in geophysical approach and currently doing research about nonlinear analysis in geothermal seismology.

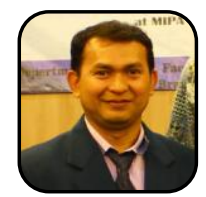

Sukir Maryanto was graduated from Physics Department, Universitas Brawijaya, Malang in 1995. He pursued his master's in Gadjah Mada University, Yogyakarta in 1996 - 2000, and graduated from his Doctoral program at Kyoto University, Japan in 2007. In 2019 he holds his Professor in volcano and geothermal field. His research is mostly related to volcanic hazards and also their relationship to geothermal exploration. He currently serves as Vice Dean of Faculty of Mathematics and Natural Sciences, Brawijaya University in General and Finance Affairs and active as a Chairman of Brawijaya Volcano and Geothermal Research Center, Universitas Brawijaya.

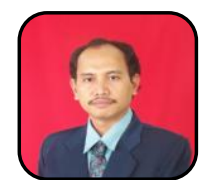

Didik Rahadi Santoso was born in Jombang, June 10, 1969. He graduated from Physics Department, Universitas Brawijaya in 1992 and holds his Master's in 1997 at Gadjah Mada University, Yogyakarta. He then pursued his
Doctoral Program and hold his Dr. Eng at Hiroshima University, Japan in 2005. He currently serves as Chairman of Doctoral Study Program at Physics Department of Universitas Brawijaya. His research is related to physical measurement and instrumentation. 